The article was published on 12 JUN 2011 in The International Journal of Art \& Design Education. [Vol.30 issue 2.] DOI: 10.1111/j.1476-8070.2011.01699.x http://onlinelibrary.wiley.com/doi/10.1111/j.1476-8070.2011.01699.x/abstract

\title{
Managing Heuristics as a Method of Inquiry in Autobiographical Graphic Design Theses
}

\begin{abstract}
This paper draws on case studies undertaken in postgraduate research at AUT University. It seeks to address a number of issues related to heuristic inquiries employed by graphic design students who use autobiographical approaches when developing research-based theses. For this type of thesis heuristics as a system of inquiry may provide a useful approach because it engages the researcher in a process that affirms imagination, intuition, subjectivity and forms of creative/critical/reflective problem solving. When employed as a framework, heuristics offers a rewarding but challenging system for connecting investigation with the researcher's personal experience. This article provides a discussion of heuristic's applications, limitations and advantages in relation to a number of recent postgraduate theses in graphic design. Through this, it seeks to provide a useful reflection on challenges and opportunities inherent within it as a system of inquiry.
\end{abstract}

\author{
Key words \\ heuristics \\ graphic design \\ autobiographical research \\ postgraduate research \\ phrõnesis \\ tacit knowledge
}




\section{Introduction}

\section{The Autobiographical Designer}

The paper is concerned with creative production research projects where postgraduate students employ the medium and devices of professional graphic design to create selfreferential statements and compositions. In these projects the graphic designer is a form of autobiographer who assumes an essential role as a character within the work. This may occur either explicitly as the subject of the design, or implicitly as the primary source and processor of thought about the project. In this regard the designer is engaged in a form of research that transcends traditional service-oriented production.

Autobiography nominates the researcher as central to an inquiry. Bullough \& Pinnegar argue that autobiography, like self-study, 'represents a trend away from modernism and its assumptions about legitimate knowledge and knowledge production toward broadening of what counts as research' $(2001,13)$.

Burdick (cited in Heller 1998, 206) has proposed that designers must consider themselves authors, not facilitators. This shift in perspective she believes implies responsibility and voice. These result in a more personal connection with design and the ability to extend professionally limited paradigms. Her beliefs have been developed by a number of theorists concerned with ideas of origination and agency in graphic design (Rock 2001; Scrivener 2000; Scrivener and Ings 2009; Wood, 2004).

Rock (2001, para. 27) argues that 'the amplification of the personal voice legitimises design as equal to more traditional privileged forms of authorship.'

Wood suggests that 'in an age of mounting ecological damage in which we often see ourselves as powerless individuals in the thrall of faceless corporations’ it is no longer appropriate for a designer, 'to deny his/her own views, ideologies and immediate wellbeing in the quest for his/her client's cause or satisfaction' $(2004,50)$.

The elevation of the self in graphic design research may be a way of addressing issues of responsibility and authenticity. However, it can also pose challenges to certain conventions of research in universities. 


\section{Contesting Values}

Normally, the autobiographical is more engaged with activating relationships between meaning and the self than it is with verifying hypotheses. Its primary values are not concerned with proof that may be contested or modified on the basis of the pursuit of a singular 'truth'.

Traditionally disciplines like graphic design have presupposed more than one contesting but effective answer to a given problem. Designers generally seek successful solutions rather than 'correct' answers. As such, their creative inquiries generally do not pursue the emphatic or verifiable.

Because of the position of subjectivity and self-reflection in much art and design research a number of writers on graduate and postgraduate study in the disciplines (Scrivener 2000; Wood 2004; Dineen \& Collins 2005), have suggested heuristics as a useful approach to creative problem solving. However, while this system of inquiry is often acknowledged as a viable research paradigm, to date little has been written about the experience of its application in graphic design theses.

\section{Heuristics as a System of Inquiry}

Heuristics comes from the Greek word 'heuriskein' meaning 'to discover' or 'find'. It is a qualitative method of solving a problem for which no formula exists. Heuristics relates to the ability to find knowledge, patterns or a desired result by intelligent, informal questioning and guess work rather than by applying pre-established formulae. As a form of inquiry it utilises sophisticated levels of informed subjectivity and tacit knowledge to solve complex creative problems.

\section{Flexibility}

Douglass and Moustakas suggest that, 'heuristics offers an attitude with which to approach research, but does not prescribe a methodology' $(1985,42)$. Heuristics does not 
focus on an established course of action but on deeply constituted experience, reflective search, sensitive overview and discovery.

Although writers like Kleining and Witt 2000; Polya 1945; Lohmann 1957, 1960; Hubka \& Eder 1996; and Douglass and Moustakas 1985 suggest ‘steps' or 'rules’ for activating or charting the intrinsically unstable nature of heuristics, these approaches differ substantially from each other.

As a method of inquiry heuristics does not lend its self easily to prescribed systems of implementation. Instead its intrinsic flexibility allows the researcher to adapt its principles to most effectively address the nature of a problem or theme under investigation. Understanding this helps to explain the slightly differing structural analyses of heuristics in methodological writing in disciplines like engineering, mathematics, health science, education, and art and design.

A heuristic inquiry places the graphic designer at the centre of the problem to be solved. It elevates his/her ability to utilise informed subjectivity and intuition as tools for discovering solutions to complex and often protean problems.

Because of this, each researcher's study may construct a different research design that operates within a heuristic conceptual framework. This design is based on self-dialogue, intuition, reflection and insightful decision-making.

Douglass \& Moustakas suggest that 'in its purest form, heuristics is a passionate and discerning personal involvement in problem solving, an effort to know the essence of some aspect of life through the internal pathways of the self' (ibid., 63).

'Internal pathways of the self' and 'the autobiographical' carry with them elevated positionings of the subjective. Their processes and outcomes are generally not provable and rarely are their systems of implementation transferable.

\section{Heuristics as Process}


That said, in the case studies undertaken in this research, heuristic inquiry normally began with a process of immersion where the researcher questioned the self in relation to the theme or problem. From here an intense questioning exercised the research area from a variation of perspectives. As data accumulated (as experiments, further self inquiries, and imported knowledge), resonances were sought. Through this process unique and useful patterns and homologies were identified and tested. It is from these connections that forms of realisation emerged.

As Douglass and Moustakas suggest,

The challenge is to examine all the collected data in creative combinations and recombinations, sifting and sorting, moving rhythmically in and out of appearance, looking, listening carefully for the meanings within meanings, attempting to identify the overarching qualities that adhere in the data. This is a quest for synthesis through realization of what lies most undeniably at the heart of all that has been discovered $(1985,52)$.

Although from this process an outcome is normally orchestrated and assembled, it does not necessarily result in a linear journey from interior to exterior thinking. Immersion in the self normally accompanies the whole process of the research and realisations are often folded back into deeper or tangential inquiries. This is done especially where reimmersion serves to advance the chances of useful discovery in the work.

Within this process, insightful questioning and decision-making is pivotal. These enable the researcher to discern patterns, homologies and resonances in the accumulating data. The success of their application, Kleining and Witt (2000) suggest, is measurable by the richness of the result, its cohesive patterns and inter-subject validity. In terms of creative practice this 'richness' may relate to the originality, coherency and internal concordance of a design.

\section{Heuristics and the Tacit}


The ability for a researcher using heuristics to discern, appraise and connect is highly dependent upon tacit knowledge. Polanyi (1967) suggests that this form of knowledge envelops the subliminal, the archetypal and the preconscious.

The problem is that tacit knowing, although adding fruitful levels of mystery, intuition and insight to problem solving, is rarely describable. For many designers tacit knowing occurs inseparably from what Rogers (1959) calls the 'actualised self'. It does not lend itself to explanation (in analytical terms), but develops as a consequence of an intuitive 'sense' of what is right. At its most sophisticated level of employment, supervisors and thesis examiners often sense tacit knowing orchestrated in highly complex but often indescribable ways. Candidates are able to intuitively connect fragments, and identify relationships. Through this they are often able to plumb unusual depths of understanding and meaning. Because they are essentially communicators, some graphic designers can use this depth of understanding as the substrate upon which sophisticatedly articulate texts are generated. By using heuristics they are able to generate more than a synthesis of the evident; they are able to draw on original insights and highly creative, autobiographically generated connections.

\section{Challenges of Heuristic Inquiry}

On the surface heuristics offers an acknowledgement of the subjective and the intuitive. It places the graphic designer at the centre of the research and suggests he/she might approach a problem acknowledging that the process may not be linear and entirely documentable.

When encountering heuristics I have often come across postgraduate design students who respond positively to descriptions that appear to parallel their personal narratives of practice. However, for many the allure of heuristics as a method of inquiry brings with it soon-discovered difficulties. These may be broadly outlined as follows:

1 Unfamiliarity with non-linear research processes 
2 Discomfort with the protean nature of a research question

3 Difficulty moving from 'task completion' to a research inquiry

4 Inability to strategise data collection and processing

5 Reluctance to address the limitations of self-referential processes

6 Discomfort with a high degree of self-searching and exposure.

\section{The Challenge of Non-linear Research Processes}

As suggested earlier, heuristics may predicate a non-linear journey. Wood suggests this is because heuristics is 'concerned with discovery, rather than with proof' $(2004,9)$.

However, linearity of investigation has been a reinforced approach to problem solving that has underpinned many design students’ previous education.

Young designers who gain entry to New Zealand university programmes of study have often experienced an education that has brought them through art, graphics and design or technology programmes in secondary schools. Often these courses tend to emphasise linear displays of thinking. To achieve good grades students often learn to re-orchestrate the narrative of their problem solving into neatly 'readable', linear processes. They do this by constructing process boards and workbooks after they have solved a problem. It is not surprising, therefore, that increasingly writers on graphic design education have argued for more discursive and reflective approaches to learning. In these approaches, process is not commoditised as a narrated product but is discussed and reflected upon as a lived experience (Davies 1996; Ehmann 2005; Ellmers, Foley \& Bennett, 2008. Accordingly, more advanced education programmes have developed approaches to design that engage reflective thinking. The challenge for these approaches is to maintain the integrity of creative research by adopting and articulating rigorous, self-conscious and reflexive approaches.

This said, it is still not uncommon to encounter graphic design graduates who have been rewarded for elegant, linear 'back-stories' that bear little or no relation to their true thought processes. More disturbingly, some of them do not know how they naturally solve problems. They do not know how to research beyond the process of reading a brief, investigating related material, generating a few concepts and then developing one into a solution that meets a listed set of criteria. When they encounter a form of inquiry that 
offers new and often unstable ways of considering and processing data, at a much deeper level, they find the lack of a prescribed formula disabling. Understandably, therefore, they are disinclined to use a system of inquiry that will take them on a journey without a road map.

\section{The Protean Nature of a Research Question}

The landscape of the creative practice thesis is generally un-traversed and uncharted. As a result, a significant number of students seek to negotiate their journey across it by minimalising the potential for disruption. In fact, many established conventions in universities emphasise the need to control or moderate the potential for disruption. Significant among these are the requirements of applications for research study that recommend a single, clearly defined question be established at the outset of the research. However, unlike many familiar research methodologies, heuristic inquiry may orchestrate several research questions that multiply and metamorphose.

Kleining and Witt suggest that when using heuristic inquiry, the topic of research is preliminary and may change during the research process. It is only fully known after being successfully explored. The topic may be overlapped by another one or turn out as part of a different problem or just disappear $(2000,2)$.

They suggest that if this happens the researcher must remain flexible and 'continue the research under new headings despite institutional and planning problems that may arise' (ibid.). Changes of this sort they suggest should be regarded as a positive sign of the accumulation of knowledge.

However, 'change' as a positive sign is an unsettling thing for many new researchers. Embracing change requires the student to become comfortable with altering his or her perceptions and frameworks. It requires the ability to overview increasingly large bodies of data and to embrace disruption as part of the fruitfulness of an inquiry. While easily embraced as a concept, in practice this is often very difficult. 


\section{Task Completion Verses a Research Inquiry}

Heuristics draws on the self as a means of generating deeper understanding and intuitive connection. As a method of inquiry for graphic designers it can make heavy demands on both time and resources. For many new researchers, especially those who have returned from years of professional practice, it requires a significant paradigm shift. Although many practicing professionals enter postgraduate study to deepen their experience and 'break ground' beyond the limiting horizons defined by clients, they often bring with them methods of problem solving formed in a pragmatic world where 'time means money'. Many of these designers have histories of successfully realising a solution through strategic decision making and employing formulae designed to achieve a rapid and satisfactory outcome. These formulae are often so deeply embedded that they are not recognised. However, such formulae rarely support deep inquiry. They are geared to generate strategically effective rather than highly innovative outcomes.

Heuristics presents to many of these researchers a seemingly unstable and unfamiliar method of inquiry. It is not geared to strategic task completion but to deep and oftentimes unstable forms of investigation.

The potential of a heuristic inquiry to increase chances of discovery is closely linked to a researcher's willingness to implement diverse and often personally disruptive approaches to work. In doing this, he/she begins to circumvent personal formulas that have historically resulted in 'competent' solutions. Disturbing preconceived and successful ways of perceiving and processing work open the research process up to higher chances of serendipity, synergy and unpredicted connection.

Sela-Smith $(2002,66)$ suggests that if heuristic research is geared primarily to the requirements of academic study, the researcher must be prepared to surrender to the inquiry, rather than control and manipulate the process so that it moves in the 'right' direction. This means that if such an inquiry is to develop in an uncompromised manner the supervisor and the candidate need to accept both its instability and the time and resource implications this can pose. 


\section{The Quagmire of Data: Strategising and Processing}

Heuristics offers a method of inquiry that encourages a multitude of considerations. Its landscape broadens before it narrows, and unless the researcher is actively aware of the nature of his/her research question at any given time they can quickly end up in a quagmire of data, wandering a plain of possibilities without sight of a horizon. This is one of heuristic inquiry's greatest challenges.

Unless the researcher is able to clearly focus on a given question and locate this question in relation to other questions within the research, the richness of investigation can quickly turn into an entanglement. Creative experiments are generated and give birth to new investigations. Increasing bodies of information are imported into the study and it begins to teeter under the escalating weight of lost direction.

It takes a sophisticated thinker with strong facilities for critical overview to manage this method of inquiry. In our experience these are often the designers who are able to intuitively locate patterns, similarities, analogies or creative connections within diverse and varied data. They can temporarily dislocate bodies of data as they focus on the potential of others. They can name at any point in their enquiry the question they are addressing and how it relates to other significant questions within the research. This is a complex skill that is not highly developed in all thinkers. For those for whom this is not a natural talent, heuristic inquiry can be distinctly non-productive.

\section{Recognising and Managing the Limitations of Self Reference}

Because heuristics affirms the personal it can sometimes offer a deceptively sheltered environment in which critical thinking is required to function. This can lead to some students failing to address the limitations of a purely self-referential approach. If they continuously fall back on their own terms of reference there is no guarantee that emerging designs are not being evaluated against limitations they don't know they possess.

Heuristic inquires tend to work effectively in graphic design research when critical decision making is able to draw upon a substantial body of personal experience. In addition to this, these inquiries can also access the objective and reasoned. Although 
these approaches do not hold traditional levels of primacy in the inquiry, they operate as options that might be brought to bear on its process.

Because graphic design is generally concerned with the development of communicative texts, a number of students also import into their research external feedback. This may take the form of end-user focus groups used to evaluate the effectiveness of emerging designs. It may also involve accessing expert opinion to offer advice on potential technological, market, and conceptual considerations surfacing in the research.

Without some form of external feedback, purely self-referenced processes can result in designs that fail to explore a wealth of available options or fall short of their communicative potential.

This said, a designer employing external feedback in a heuristic inquiry needs to be vigilant. Sela-Smith in her critique of Moustakas's method notes that a 'confusion of... different perspectives and different meanings, can fully disorient the researcher doing self-inquiry’ (2002, 71). Unless feedback is drawn back into the self (as opposed to simply being applied to the emerging design) the system of inquiry can become disconnected. The power of the subjective search can shift to an objective analysis of the created phenomena. This can result in a work in the final stages of its realisation, losing much of its integrity and idiosyncratic 'voice'. This is because, if one applies critique to the emerging artifact instead of the question, the outcome can become disconnected from the wealth of tacit knowing that brought it into being.

This is a challenging issue for supervisors. In many cases, when working with a candidate employing a heuristic inquiry, it is useful to remind oneself that such an inquiry is an orchestration of questions. If feedback is framed as questions (rather than advice), and a response is not asked for as an instant response, there is a higher chance that reflection may be taken back into, and reprocessed inside the self.

\section{Exposure of the Self}

Because it is so aligned to autobiography, heuristic inquiry is self-exposing. Its journeys through 'internal pathways of the self' go far deeper than simply reflecting on actions. A heuristic inquiry delves into the researcher's fundamental concepts of meaning, 
knowledge and identity. It draws on these in passionate and demanding ways in its pursuit of deeper levels of inquiry.

Scrivener (2000) speaks of creative production theses in art and design as being less concerned with generating 'new knowledge' and more with making a significant contribution to human experience or understanding.

As visual communicators often working at very sophisticated levels, some researchers in graphic design activate autobiography as a method of engaging this understanding. However, knowing the transactional nature of much creative research, one is aware as a supervisor that the journey these students undertake may be as much an emotional experience as an intellectual one. A supervisor needs to be aware that not all students who are intellectually ready to undertake creative production theses are emotionally prepared for the challenges of autobiographical approaches. Thus a careful consideration of what heuristics requires on an emotional, intellectual and management level is imperative. This is because, when rigorously applied, the autobiographical has the potential to unearth and expose personal issues to scrutiny.

In relation to this, self-inquiries are distinctive in that the researcher is also the participant. However, many Universities ethics guidelines for research tend to focus upon the safety of co-participants. This presents issues for supervisors who are responsible for helping a candidate navigate both the question (in its emerging manifestations) and the self. Such a relationship requires a high level of trust and where there are no ethics guidelines, the supervisor and candidate need to carefully talk through the potential implications of the research question. They also need to commit to ongoing, attentive, and open dialogue. If this commitment is not made heuristic inquiries can run in to difficulties.

\section{Applications of Heuristic Inquiry}

Because it is evident that heuristic inquiry may not suit all researchers who engage in creative practice, it is useful to briefly reflect on examples of research projects that have 
been realised through its application. In doing this I hope to briefly contextualise some advantages that a heuristic inquiry may provide.

Three recent case studies may serve as illustrations.

\section{Lamia Aziz}

\section{Questioning the Dreams of Gilgamesh}

Because of its autobiographical nature, heuristics can be used to reach rich but often vulnerable parts of both the researcher and the researched. Although this can be problematic for some students, for others the creative fusion of the self and external phenomena can lead to very profound results.

This candidate's (2007) Honours dissertation, 'Questioning the Dreams of Gilgamesh' explored the ancient Sumerian Epic of Gilgamesh and employed reflections on her personal experiences as an emigrant from Iraq in the development of Artist's Book. The work contained twelve illustrations that fused traditional etching with digital technologies. The images integrated two voices. The first was that of the original epic and the second was the candidate's voice as an artist who lost her home and then, in the space of a year's study, both her father and brother in separate bombings.

To develop the potential of this project, the candidate's personal reflections on war in contemporary Iraq were brought into discourse with the consequences of dreams resulting from Gilgamesh's quest for power, territory and meaning.

\section{The Protean Research Question}

Before undertaking the project the candidate and supervisor met many times. As a recent immigrant to New Zealand Lamia was uncertain of the political safety of expressing what she considered 'dangerous' personal/political opinions. In discussions she talked about being torn between a learned fear of speaking out, and a need to express the substance of her suffering.

As a consequence, from the outset of the research we embedded a provisional embargo on the dissertation (for a negotiable period of time). If, once the dissertation was completed and assessed, the candidate felt uneasy about its appearance in the public 
domain, the work could be protected. An embargo relating to aspects of the practical work is still in place and has been respected in selecting what has been included in this article.

At the outset of the project the candidate engaged in a process of what Douglass and Moustakas (1985) call 'immersion'. In this state she drew into herself a question that asked 'What are the resonances between a story I grew up with (the Epic of Gilgamesh) and my experiences as a woman who encountered war on the same soil on which this story occurred?'

As the research developed this question began to metamorphosise into more complex concerns including 'What is the graphic nature of male heroism when one compares Gilgamesh's hunger for power to that of Sadam Hussein?' and 'Are there parallels in the way the suffering of people under these leaders might be illustrated?' These questions operated inside a network of other inquiries into technological, narrative and stylistic concerns.

\section{'Knowing' and the Internal Pathway of the Self}

After years of being politically and emotionally unable to discuss her feelings and experiences, the candidate was initially cautious about 'voicing' her opinion openly. This is because her process and outcomes made her personally vulnerable and publicly accountable.

But she persisted. A heuristic inquiry validated a source of knowing and analysis that she could not access in recorded data. By locating her questioning in an internal pathway of the self, she was able to engage the nebulous nature of memory and exercise connections in very sophisticated ways between experienced customs, cultural depictions and emotional resonances.

The result was a design that crossed language and cultural divisions. It articulated a powerful, personal and political statement, and in its transactional nature drew into close connection the character of the researcher and the nature of her research. In the conclusion of her exegesis the candidate wrote:

This project has been a huge challenge for me. It has been more than an academic study, and it has been more than the production of a series of illustrations. It has 
been a reflection on very deep and profound experiences, brought out into the light of day through their discourse with the dreams of an ancient Sumerian king. (Aziz 2007, 60)

Significantly when the candidate developed this research into a Masters thesis two years later, she designed a book for children that brought to light the conflicts between the original epic and the lived experience of contemporary Iraqi people. In realising this text she again adopted a heuristic enquiry. Although this new work surfaced from a very different body of research, she again noted in her exegesis the strong relationship between the researcher and the research.

The thesis is subjective. It would be impossible to realise in any other way. Because of this it is also biased, but out of that bias comes a voice that seeks to relate, through loss, some of the beauty and magnificence of what it is to be Mesopotamian. (Aziz 2010, 67)

Lamia did not use external feedback as a significant method for refining the communicative potential of her work. She was already a well-established book illustrator with publications in print in many countries. Accordingly, her critical facilities when applied to refining her illustrations were highly developed. Instead of accessing external feedback, she pursued intervalidity in her research by a process Sela-Smith $(2002,79)$ describes as 'surrendering to the process that is pushing itself into the consciousness of the researcher, allowing the process to unfold and then noticing results in expansion of self awareness, deepening of self-understanding, and of self transformation that others can experience in the story.' Accordingly, Lamia's work across three years remained in a state of constant metamorphosis. As she changed so did her illustrations. The impact of the deaths of her family members darkened and deepened resonances within them, a journey back to her homeland to gather scattered remnants of photographs and documents further fractured and personalised the structure of her work. Significantly, this journey also intensified the highly personalised voice she adopted in writing the exegesis that accompanied the project.

\section{Insert figure 1 and caption here}


Figure 1: Acid etching with embedded dye transfers (2007). An early experiment for Dream number 9: The death of Enkidu depicting public grieving. The image orchestrates tensions between a photographic record of a recent funeral and an illustration of mass mourning. These are fused inside a palette of burnt colours indicative of the artist's home after war destroyed all signs of vegetation. [Image courtesy of the designer].

\section{Lucas Doolan}

The Sublime Ruin: Enigmatic Feminine

In a very different way, Lucas Doolan, who completed his Masters thesis in 2008, employed heuristic inquiry as a method of realising a number of designs that considered the nature of the sublime ruin. In actualising this work he examined the disintegration of four Judeo-Christian feminine metaphors: the Queen of Heaven, Lilith, Sophia and the Whore of Babylon. His designs were produced to make manifest, through image and text, the way eroded fragments of narrative constitute an excess of meaning.

In discussing his rationale for adopting a heuristic system of inquiry the candidate said:

Heuristics served this present research project because it was my desire to create [discover] a body of work that was highly original. To do this I needed to move beyond the formulae that had produced competent but stylistically similar work for me in the past. I also required a methodology that was flexible, non linear, and might embrace disruption. Heuristics had a structure that enabled discord to be accommodated. This was important because solutions in this project sometimes occurred via antithesis and illogic (Doolan 2008, 15).

\section{Creating an Environment for Risk-taking}

Because heuristics is not a prescribed methodology but a paradigm inside which disruption and illogic might profitably function, the candidate was able to create connections between highly disparate and often antithetical ideas. This was because he was able to intuitively find patterns and homologies resonating inside very disparate sources. Gnostic, Hebrew and Apocryphal texts were brought into play with the translucency of oiled resins, the meanings of pulp fiction and the rhythms of the Fibonacci series. 
By opening the chances of discovery up to unconventional synergies, the researcher was able to explore alternative framings of both the ruin and the religious metaphor. The questions surfacing from his inquiry were complex and multi-faceted. In response to these, his work moved through typographical, mathematical, abstract and figurative discourses before finally arriving at resolution.

Lucas was not a researcher given to group processing of ideas and he was very selective about the people with whom he discussed his work. This was because he was not studying The Sublime Ruin as a phenomenon but as an internal discussion with the self. Discords and harmonies in his life spoke to and shaped those in his work. Because he saw his journey as both emotional and artistic, any critique he offered on his work could not be divorced from a critique of himself. Lucas was concerned with an issue Sela-Smith raises in relation to heuristic inquiries. She argues, because a topic may be emotionally challenging 'the researcher may unconsciously resist the actual personal problem and consider something less threatening' $(2002,65)$.

Lucas fought to hold onto the integrity of his questions. He saw periods of isolation as integral to his ability to take risks because these immersions shielded his thinking from outside doubt and influence. This was important because initially his most productive and creative connections tended to be precarious and illogical. Because they could be easily misunderstood until he had time to test, critique and refine them, they were vulnerable to being discarded. Moreover, he knew that he could easily walk away from complex problems and embed 'styled answers' that while apparently elegant, would reduce his work to a superficial series of compositions.

Because of his fears surrounding the maintenance of authenticity in his research process Lucas requested that supervision sessions become solely question based. By doing this, he was able to reflect on issues he may not have hitherto considered. He would then withdraw and reflect on his (sometimes contradictory) responses inside the state of immersion from whence he generated solutions. 


\section{Deleted section on Reviews of Knowledge}

\section{Breaking Established Formulae}

Lucas deliberately adopted a destabilising approach to his research project in an effort to break what he perceived to be the 'limitingly successful formulae' that had resulted in him recently producing bodies of very similar work. Therefore, in this project, his research processes were marked by multiple variations of perspective taken to protean research questions. These, however, operated inside a clearly articulated concern with finding relationships between theological metaphors and conceptions of the ruin.

Figures 2-6 (2007-8)

A selection of slowly synthesising points of inquiry into the Whore of Babylon as a sublime ruin. Demonstrating a variation of perspectives on the central question, experiments consider the figure as type, artifact, photographic collage, tiered resin painting, and digital inkjet print. [Images courtesy of the designer].

\section{Insert figure 2 and caption here}

Figure 2: One of a number of early experiments that considered the Whore of Babylon as a disintegrating metaphor, seen initially as type and later as the decay of the 'book'.

\section{Insert figure 3 and caption here}

Figure 3: One of several experiments that considered the Whore of Babylon as technology moving [left to right] from the sublime to the ruin.

\section{Insert figure 4 and caption here}

Figure 4: One of several photographic studies considering the Whore of Babylon as a photographic ruin.

\section{Insert figure 5 and caption here}

Figure 5: Digital print with painted surfaces considering the Whore of Babylon fused with an environment of ruined, cryptic and mathematical references. 


\section{Insert figure 6 and caption here}

Figure 6: Final abstract interpretation for the Whore of Babylon (digital inkjet print).

The process of this inquiry was complex and interrogative. It orchestrated the unstable inside the autobiographical because the candidate saw from the outset that 'the research needed to heighten irrationality in the process of framing and making work,' in doing this he was using heuristic inquiry to 'break ritual and formula in [his] problem solving strategies' (Doolan 2008, 130).

The final prints carry traces of his navigation. Fragments gathered on a complex journey are composed into a coherent design that has moved beyond the figurative to embrace the mathematical, metaphysical and emotional. The enigmatic feminine is a sublime ruin, but so is the journey of her realisation.

\section{Mardo El Noor}

\section{Narratwist: Alteration of Meaning in a Short Film Text}

The third Masters thesis project was completed in 2009. The candidate sought, through the integration of sound, image and narrative, to develop a short film that disrupted viewers' expectations of denouement.

When he began the project, the candidate's knowledge of filmmaking on a technical and narrative level was limited. Despite this he wanted to explore his abilities as a writer, director, art director, typographer, soundscapist and editor.

\section{Opening a Research Question up to Disruption}

Given that an effective heuristic inquiry in design normally requires a substantial framework of experience from which one might make informed subjective judgments, the decision to employ this approach may initially have been considered problematic. However, beyond the technical limitations of his knowledge of filmmaking, the candidate was already an internationally renowned recording/mixing artist, and he clearly evidenced an ability to exploit very complex technological synergies. He could also 
overview multiple questions and orchestrate complex layers of information with relative ease.

The candidate knew he was seeking a flexible form of inquiry because he could not predict the exact nature of his journey. He knew his approach would be largely intuitive and probably disrupted by what he didn’t know. He knew it would involve building and applying knowledge, and creatively synthesising a 'vision' that would be highly prone to disruption.

And this is what happened. The decision to explore the potential of silhouetted characters in his film was a direct consequence of limited lighting facilities. In addition, the shallow depth of field in the work occurred because the candidate could not afford to build these environments as sets. Finally, the highly layered look of the film was a compensation for the fact that time and budget precluded him from gaining additional training in the use of 3D software. As a consequence the candidate built the world of the film in Photoshop. What is significant about the inquiry is that technological limitations facing the research were simply reframed as opportunities, and, as Kleining and Witt (2000) suggest, these were accommodated in the project's journey because they were regarded as positive approaches for accumulating knowledge.

\section{Strategising Data Collection and Processing}

Although the flexibility that heuristics afforded this project was evident in its ability to negotiate technological challenges, what was more distinctive was the inquiry’s ability to accommodate unique ways of thinking. In his discussion of the project's research design the candidate noted:

At the outset of the project my concern was to maintain a high level of flexibility in my practice. This demanded a research design that would enhance the organic, synthetic and non-linear nature of my approach to creative inquiry. The research design needed to activate (and validate) both the tacit and the passionate so they might be employed in considering and processing highly complex and multifaceted bodies of information. I also needed an approach that would work in other than the written and spoken word. I tend to think at sophisticated levels in sound and image. The complexity of many ideas involved in my work is slowed down 
through forced translation into writing. By avoiding this translation, I can process complex bodies of knowledge inside image or sound-based environments. By doing this I can make connections between bodies of information that may be distorted through 'languaging' into words. I am also able to find concordances and patterns by intuitive consideration of concepts inside the environment in which they were conceived (as imagined images). In many cases these are ideas for which no translation into words exists (El Noor 2009, 28).

The candidate's work processes were multilayered. He created the sound design in parallel to his development of dressed environments. Dialogue was constantly rerecorded and remixed as he refined the project and altered its emphases.

This meant that he was locating patterns and connections through an intuitive process of cross-fertilisation. His ability to strategise data collection and processing was tied to congruencies surfacing within the work. His ability to locate patterns and resonances may be likened to Kleining \& Witt's (2000) observation that when processing complex phenomena, once the homogeneous is identified and extracted, what remains is paralysed. The process of connection and disconnection was evidenced in the environment in which the candidate worked. His studio walls were festooned with strange objects, half-rendered ideas and printouts of sequences he was developing. But this was not a three-dimensional rendering of a mind map. Many of the objects had no other purpose for being there than they had attracted his attention. They were not bridged in a tangible way to other ideas. They simply dwelt in an environment of suggestion and possibility. When they no longer 'felt right' they were removed and something else took their place.

In discussing his relationship to the emergence of ideas the candidate says:

The immersion of the self typified my approach to the project. I worked an average of twelve hours a day over a year and a half, shifting between writing, directing, and designing every detail of the film. Throughout most of the project, I spent more time within the film's diegesis than in the real world. In doing this, I was trying to imagine (and feel) how this world might look and sound. I lived inside it to understand how its textures and light might interact, how its characters 
might move, how buildings and signage might operate in discursive ways, and how colour might demarcate and connect environments (El Noor 2009, 31).

\section{Review and feedback}

Although Mardo’s film was selected for a number of national and international film festivals, the juried selections did not form part of his project's critical development as a body of research.

Instead the candidate engaged three distinct methods of feedback. The first was collaborative. Although he wrote a screenplay and director's notes, when working with actors Mardo encouraged them to respond to core ideas with the intention of opening up potentials within the work. Feedback from these co-participants was embedded in certain shots when he felt it might work. However Mardo made a point of shooting scenes a variety of ways so a number of potentials could be weighed against the core concerns of the work once he had them back in the immersive state of his studio.

The second form of feedback Mardo sought was from selected professional writers and directors whose work he respected. In discussions, emerging treatments were rarely laid out as a whole. Instead he raised specific questions relating to problems he was encountering. Sometimes these were narrative-based, sometimes technical, and sometimes related to iconography. In each case however, the whole and its connections remained sheltered in the interior spaces of the self.

Finally, as the film took form the candidate had concerns regarding the clarity of its narrative. Because the work orchestrated a dual narrative and its visual voice was very complex, he became worried that it could slip into a congestion of mixed readings. To check on its communicative quality he showed drafts of his film to people who had not seen it before. Then he asked them to tell the story back to him. What is interesting here is that as a researcher, he was not seeking an analytical critique but reflecting on a narration of his narration. The story retold, helped him to see what elements were 
accentuated. If there were areas of confusion these became evident in the retelling because they did not sit in concord with the narrative he believed he had created. These retellings were pulled back into the private world of his emerging film and adjustments were made until he felt that an issue had been addressed. Once this was done he would show the restructured film to another set of viewers. It was through this process of reflecting on independent retellings that he eventually refined the film's narrative discourse.

\section{Phrõnesis and actualising the self}

In research like this sometimes the line between the researcher and the researched becomes permeable. Complex problems become as much a concern of the research as they are a concern of the self. In cases like these we sometimes see evidenced what Aristotle called phrõnesis. Garrison $(1997,73)$ notes this need for, and processing of, new skills 'involves developing the habits, abilities, thoughts, ideals, technical mastery and virtues of the practice. Becoming an expansively more competent practitioner requires disciplined practice and eventually self-creation that calls into existence a new and better self.'

The calling into existence of a 'better self' is something that combines the ability to both solve problems and take responsibility for one's actions. This is a significant accomplishment.

However, this process is often costly. In truth the candidate 'lived' in the studios for eighteen months. Douglass \& Moustakas’s (1985) 'immersion of the self' involved halfeaten meals going cold in front of the computer, getting sick and inspired, angry and elated. It meant frustrations and alterations because what was initially envisioned could not be realised. It meant new discoveries.

Finally it meant relationships were formed, knowledge learned and endurance tested ... and this resulted in a deeply resolved, elegantly cohesive and highly complex body of work that reached far beyond anything the candidate had previously created. It journeyed through immersion and synthesis to realisation, but not as a linear progression. His research was a network of re-visitings, re-thinkings and unique synergies. 
What is significant, however, is that the 'better self' who emerged from this undertaking never appeared on academic transcripts, nor did he feature in examiners' reports. Knowing that intellectual disobedience and courage must be underpinned with tenacity, that editing is something applied both to narrative and thought, and that human beings are not just participants but part of the fabric of the creative process, are indicative of significant understandings. Douglass and Moustakas state that, 'Self-experience is the single most important guideline in pursuing heuristic research' $(1985,46)$. If this is true, one is left expecting a great deal of heuristic inquiry because it has the potential to enable both creative inquiry and the growth of the researcher as a human being. The autobiographical becomes linked to a sense of responsibility.

Figures 7-9:

Stills from the short film In the Name of Art. [Images courtesy of the designer].

\section{Insert figure 7 and caption here}

Figure 7: Exterior view of the protagonist's apartment

The short film contained 150 individual plates, of which three are presented here. These plates contained orchestrated layers of imagery and type between which small, animated sequences (like the flicker of a street light) were embedded. It was from the structure of these plates that certain similarities were translated into the film's soundscape. This meant the film's highly distinctive sound design was also multi-layered. Within this layering were embedded small accents of foley used to draw attention to details within the narrative.

\section{Insert figure 8 and caption here}

Figure 8: Interior of the white room where the inner story of the film unraveled. Technical limitations discovered during early experiments meant that anticipated effects from chromakeying and lighting could not produce the 'look' the designer wanted. Consequently, he experimented with converting the whole narrative to silhouette. This was seen initially as a frustrating compromise, but once the imagery was 'sandwiched' between layers of the film's environment, a highly distinctive aesthetic emerged. 


\section{Insert figure 9 and caption here}

Figure 9: Later in the research, experiments with silhouette lighting gave rise to further investigations relating to the potential of incongruity. Here, in an interior of her apartment we see the protagonist shot in silhouette but reflected back in chiaroscuro.

\section{Conclusion}

Because these candidates knew that two independent, external examiners would assess their projects, they were aware that they needed to develop a clear voice when articulating their research design. Accordingly, the written exegesis that accompanied their project was normally voiced in the first person and often contained a personal positioning statement. This document did not simply describe and critique the application of heuristics; it illustrated renegotiations within the inquiry in relation specific problems and critical ideas encountered in the research journey.

While a heuristic inquiry may involve the traversing of internal pathways of the self, its outcomes (the exegesis and created work) are required to position themselves in the public domain as articulate, communicative texts. Therefore, from the outset, candidates were aware of the exposed nature of the inquiry and its public outcomes. Each of the designers in these case studies accepted that authorship brings with it a relationship to unknown the readers.

When Rock (2001) argued that a graphic designer might be an author who engages in work that transcends traditional service-oriented commercial production, he recognised that the resulting designs might engage new levels of responsibility. In postgraduate research this type of designer may be required to access and process knowledge on very deep levels. In achieving this, a heuristic inquiry as a means of discovering knowledge may pose unique challenges, but it also offers a number of distinct advantages.

- It validates personal experience. In creative production theses, imagination and tacit knowing can be activated, and intuition used to connect and evaluate often intangible elements like recollection, experience and emotional resonance. 
Thinking can occur in a 'sympathetic' environment where creative rituals and problem-solving processes are already sophisticated and well established.

- Heuristic inquiry offers flexibility. Because it does not presuppose a finite question, it has the ability to adjust in relation to new discoveries surfacing in the research. In this regard it does not position contextual knowledge as an area to be defined at the outset of a project. Instead, it integrates and exploits the potential of existing knowledge in relation to unfolding questions and discoveries. This enables the researcher to work in very responsive ways.

- Because heuristic inquiries do not presuppose a set formula, a designer can orchestrate distinctive, discordant and unconventional approaches to a project. By actively disrupting established personal formulas, he/she can heighten levels of risk taking and consciously push ways of processing knowledge into unfamiliar areas. This may increase the chances for discovery in the project.

- Finally, because of the central position of the 'self' in heuristic inquiry, it may be possible to draw into close proximity relationships between an inquiry and the development of the person. Mooney $(1957,166)$ discussed the nature of research such that its pursuit might interface 'with the acceptance and fruitful development of one’s self.' As graphic design becomes increasingly concerned with the implications of, and responsibility for, what it produces, this relationship becomes an increasingly significant consideration.

Heuristics is demanding, but its potential to progress highly gifted graphic designers beyond the formulas that have brought them to levels of competence is considerable. Questions regarding its selection as a method of inquiry, however, should be considered not only in relation to the research, but also in relation to the researcher. Bullough \& Pinnegar say, 'Who a researcher is, is central to what the researcher does' $(2001,13)$. Without considering this idea critically, we run the risk of recommending research paradigms that are assumed to enhance creative discovery, when they may in some cases disable or inhibit quality research. 


\section{References}

Aziz, L. (2007) Questioning the Dreams of Gilgamesh. Unpublished Art \& Design Honours Dissertation. Auckland: AUT University.

Aziz, L. (2010) Gilgamesh, the hero of Mesopotamia (online). Available at:

http://aut.researchgateway.ac.nz/handle/10292/813 (accessed $14^{\text {th }}$ June 2010).

Bullough, R. V., \& Pinnegar, S. (2001) Guidelines for Quality in Autobiographical Forms of Self-Study, Educational Researcher, Vol. 30, No. 3, pp.13-21.

Davies, A. (1996) Assessment and Transferable Skills in Art \& Design, International Journal for Art \& Design Education, No. 3, pp. 327-331.

Dineen, R, \& Collins, E. (2005) Killing the Goose: Conflicts between Pedagogy and Politics in the Delivery of a Creative Education, JADE Vol. 24, No.1, pp. 43-52.

Doolan, L. (2008) The Sublime Ruin: Enigmatic Feminine (online). Available at: http://aut.researchgateway.ac.nz/handle/10292/420 (accessed $6^{\text {th }}$ June 2010).

Douglass B. G. \& Moustakas, C. (1985) Heuristic Inquiry, Journal of Humanistic Psychology, Vol. 25, No. 3, pp. 39-55.

Ehmann, D. (2005) Using Assessment to Engage Graphic Design Students in their Learning Experience, 2005 Evaluations and Assessment Conference, University of Technology, Sydney.

Ellmers, G., Foley, M. \& Bennett, S. (2008) Graphic Design Education: A Revised Assessment Approach to Encourage Deep Learning, Journal of University Teaching \& 
Learning Practice, Vol. 5, No.1, Article 7. Available at:

http://ro.uow.edu.au/jutlp/vol5/iss1/7 (accessed $6^{\text {th }}$ June 2010).

El Noor, M. (2009) Narratwist: Alteration in Meaning in a Short Film Text (online). Available at: http://aut.researchgateway.ac.nz/handle/10292/408 (accessed $14^{\text {th }}$ June 2010).

Garrison, J. (1997) Dewey and Eros: Wisdom and Desire in the Art of Teaching. New York: Teachers College Press.

Heller, S. (1998) The Education of the Graphic Designer. New York: Allworth Press.

Hubka, V. \& Eder, W. E. (1996) Design Science: Introduction to the Needs, Scope and Organization of Engineering Design Knowledge. London: Springer-Verlag.

Kleining, G. \& Witt, H. (2000) The Qualitative Heuristic Approach: A Methodology for Discovery in Psychology and the Social Sciences. Rediscovering the Method of Introspection as an Example, Forum Qualitative Sozialforschung / Forum: Qualitative Social Research (on-line). Available at: http://www.qualitative-research.net/fqs-texte/100/1-00kleiningwitt-e.pdf (accessed 10 June 2010).

Lohmann, H. (1957) The Importance of Methodology for Education in Technology. Berlin: Die Fachschule.

Lohmann, H. (1960) To the Theory and Practice of Heuristics in Engineering Formation (Zur Theorie und Praxis der Heuristik in der Ingenieurerziehung). TH Dresden: Wiss. Zeitschr, pp. 1059 -1281.

Mooney, R. (1957) The Researcher Himself, Research for Curriculum Development, 1957 Yearbook, Association for Supervision and Curriculum Development, Washington, pp. 154-186. 
Polanyi, M. (1967) The Tacit Dimension. N.Y.: Doubleday.

Polya, G. (1945) How to Solve It: A New Aspect of Mathematical Method. Princeton, NJ: Princeton University Press

Rock, M. (2001) What Does it Really Mean to Call for a Graphic Designer to be an Author? (online). Available at: http://eyemagazine.com/feature.php?id=30\&fid=258. (accessed 15th June 2010).

Rogers, C. R. (1959) A Theory of Therapy, Personality, and Interpersonal Relationships, as Developed in the Client-centered Framework, in S. Koch [Ed] Psychology: a study of a science. New York: McGraw-Hill, pp. 184-256.

Scrivener, S. (2000) Reflection In and On Action and Practice in Creative-Production Doctoral Projects in Art \& Design: The Foundations of Practice-Based Research (online). Available at: http://sitem.herts.ac.uk/artdes_research/papers/wpades/vol1/scrivener1.html (accessed $11^{\text {th }}$ June 2010).

Sela-Smith, S. (2002) Heuristic Research: A Review and Critique of Moustakas's Method. Journal of Humanistic Psychology. Vol. 42, No. 23. pp. 53-88

DOI: $10.1177 / 0022167802423004$

Wood, J. (2004) The Culture of Academic Rigour: Does Design Research Really Need It?', The Design Journal, Vol. 3, No. 1, pp. 44-57. 